\title{
A Balanced Network: Transcriptional Regulation in Pluripotent Stem Cells
}

\author{
Lingyi Chen ${ }^{1 *}$ and Li-Feng Zhang ${ }^{2 *}$
}

${ }^{1}$ The State Key Laboratory of Medicinal Chemical Biology and College of Life Sciences, Nankai University, Tianjin 300071, China

${ }^{2}$ School of Biological Sciences, Nanyang Technological University, Singapore 637551

\begin{abstract}
Embryonic stem cells (ESCs) hold great promise for regenerative medicine. It has been an active research field to understand the molecular mechanisms underlying the pluripotency of ESCs. Self-renewal of ESCs relies on maintaining the unique transcriptional profile of ESCs, while differentiation of ESCs requires a flexible transcriptional profile so that it can be altered in different types of cells. Therefore, transcriptional regulation plays important roles in pluripotency. In this review, we summarize recent discoveries on how transcriptional regulation contributes to pluripotency maintenance in ESCs. We emphasize the functions of transcription factors in pluripotency maintenance, as well as in $\mathrm{X}$ chromosome inactivation and somatic cell reprogramming.
\end{abstract}

Keywords: Embryonic stem cells; Pluripotency; Transcriptional regulation; X chromosome inactivation; Nanog; Oct4; Sox2

\section{Introduction}

Embryonic stem cells (ESCs) are derived from the inner cell mass (ICM) of the blastocyst, and are able to self-renew indefinitely while maintaining the potential to differentiate into all types of cells in the body [1-3]. Thus, ESCs hold great promise for regenerative medicine. The underlying molecular mechanism for pluripotency is a fundamental question being actively investigated. In the past few years, many mechanisms contributed to pluripotency have been revealed, including transcriptional regulation, epigenetic modifications, chromatin dynamics, signaling pathways, and microRNAs [4-6]. ESCs and somatic cells share almost identical genetic information, the genomic DNA. Pluripotency, the unique property of ESCs, is realized through selective gene expression. Therefore, transcriptional regulation plays a pivotal role in pluripotency regulation. Consistently, through ectopic expression of several transcription factors, somatic cells can be reprogrammed back to the pluripotent state [7-9]. In this review, we summarize recent discoveries how transcriptional regulation contributes to pluripotency maintenance in ESCs, with an emphasis on the function of transcription factors. We also discuss the co-operation of transcription factors with epigenetic factors and signaling pathways in pluripotency maintenance, as well as the roles of pluripotency transcription factors in $\mathrm{X}$ chromosome inactivation and somatic cell reprogramming.

\section{Core Transcriptional Circuitry for Pluripotency}

Early genetic experiments have identified critical pluripotency factors essential for pluripotency establishment in embryos [10-13]. Oct4 was the first identified pluripotency factor. Oct4 null embryos develop to the blastocyst stage. However, the ICM cells of Oct4 null embryos are not pluripotent. Instead, they are diverted to a trophectodermal fate. Thus, Oct4 null ICM cells fail to give rise to embryo or ESCs [11]. Another key pluripotency factor is the HMG-box transcription factor Sox2, which heterodimerizes with Oct4 to regulate their downstream target genes [14-16]. Similar to Oct4 depletion, knockout of Sox2 leads to peri-implantation embryonic lethality [13]. When cultured in vitro, ICM cells with Oct4 or Sox2 deficiency differentiate into the trophoblastic lineage, consistent with the transcriptional activity of the Oct4 and Sox2 heterodimer [11,13]. Nanog was first identified as a factor allowing ESC self-renewal independent of leukemia inhibitory factor (LIF) [10,12]. Nanog null embryos die around implantation due to lack of epiblast. Nanog null ICM cells fail to proliferate in vitro. Instead, they differentiate into parietal endoderm-like cells [12].

Consistent with their roles in pluripotency establishment in developing embryos, Oct4, Sox2, and Nanog are important for pluripotency maintenance in ESCs. Knockdown of Oct4, Sox2, or Nanog causes ESC differentiation [17-21]. Interestingly, self-renewal of ESCs requires the precise expression level of Oct4. Enhancing Oct4 expression by less than two-fold induces primitive endodermal and mesodermal differentiation. In contrast, repression of Oct4 results in differentiation to trophectoderm [17]. There is some controversy on the essential role of Nanog in pluripotency maintenance. Over-expression of Nanog allows mouse ESC self-renewal in the absence of LIF. No ESCs can be derived from Nanog null embryos $[10,12]$. These data suggest that Nanog is essential for pluripotency. However, Nanog null ESCs were established by genetic depletion in ESCs. These Nanog null ESCs can self-renew indefinitely in the absence of Nanog, and contribute to fetal and adult chimera. It seems that Nanog is dispensable for the maintenance of ESC pluripotency in culture. Nevertheless, Nanog null ESCs are not fully pluripotent. They are prone to differentiate in culture, and fail to form germ cells in chimera mice [22].

To understand how Oct4, Sox 2 and Nanog regulate pluripotency in ESCs, several groups carried out genome wide binding site analyses of these three factors, and found that Oct4, Sox 2 and Nanog not only bind to their own promoters, but also occupy at one another's promoter, thus forming a core positive feedback circuitry for pluripotency. These core pluripotency factors activate the expression of protein-coding genes and microRNAs involved in pluripotency maintenance. Meanwhile, Oct4, Sox 2 and Nanog repress many key transcription factors for differentiation and development, preventing ESCs from differentiation

*Corresponding authors: Lingyi Chen, College of Life Sciences, Nanka University, 94 Weijin Road, Tianjin, China, Tel: (86)-22-23505821; Fax: (86)-2223505821; E- Mail: lingyichen@nankai.edu.cn

Li-Feng Zhang, School of Biological Sciences, Nanyang Technological University, 60 Nanyang Drive, Singapore 637551, Tel: (65)-6316-7094; E- Mail: zhanglf@ntu.edu.sg

Received April 12, 2012; Accepted May 07, 2012; Published May 09, 2012

Citation: Chen L, Zhang LF (2012) A Balanced Network: Transcriptional Regulation in Pluripotent Stem Cells. J Stem Cell Res Ther S10:004. doi:10.4172/2157-7633. S10-004

Copyright: (c) 2012 Chen L, et al. This is an open-access article distributed under the terms of the Creative Commons Attribution License, which permits unrestricted use, distribution, and reproduction in any medium, provided the original author and source are credited. 
[23-27]. Moreover, Oct4 and Sox2 appear to participate in cell fate determination upon differentiation. Oct 4 promotes mesendodermal differentiation, while Sox 2 facilitates neural ectodermal differentiation [28].

\section{Other Pluripotency-associated Transcription Factors}

In addition to the core transcriptional circuitry, many other transcriptional factors, including Tcf3, Smad1, Stat3, Sall4, Dax1, Esrrb, Nr5a2, Tbx3, Zfx, Ronin, Klf4, Foxd3, Foxo1, Foxp1, Prdm14, Zic3, Nac1 and Zfp281 have been demonstrated to be involved in pluripotency maintenance [29-55]. Consistent with their role in pluripotency maintenance, the expression of majority of these pluripotency-associated transcription factors are directly regulated by Oct4, Sox2 and/or Nanog (Table 1) [26]. Among these pluripotencyassociated transcription factors, Tcf3, Smad 1 and Stat 3 are transcription factor associated with signaling pathways. We will discuss their roles in the section of integration of external signals into transcriptional activity.

The genome wide binding profiles of pluripotency-associated transcription factors in ESCs, including Dax1, Esrrb, Nr5a2, Tbx3, Zfx, Ronin, Klf4, Foxp1, Prdm14, Nac1 and Zfp281, have been established [25,26,39,45,47,51,56-58]. These pluripotency-associated transcription factors, except for Ronin, bind to the promoters of Nanog, Oct4 and/or Sox2 (Table 2). Most of them contribute to pluripotency maintenance by stabilizing the core transcriptional circuitry. In addition, these pluripotency-associated transcription factors co-occupy many target genes of Nanog, Oct4 and Sox2, suggesting that they might also facilitate activating genes involved in pluripotency maintenance and repressing genes required for differentiation $[25,26,39,45,47,51,56,58]$. However, not all the pluripotency-associated factors enhance the stability of the core transcriptional circuitry. For example, Zfp281 binds to the promoters of Nanog, Oct4 and Sox2, but acts as a repressor for the key pluripotency genes $[25,44,45]$. The interaction between Dax1 and Oct4 suppresses the transcriptional activity of Oct4 protein [32]. Negative

\begin{tabular}{|c|c|c|c|}
\hline Genes & Oct4 & Sox2 & Nanog \\
\hline Sall4 & + & + & + \\
\hline Dax1 & - & + & + \\
\hline Esrrb & + & + & + \\
\hline Nr5a2 & + & + & - \\
\hline Tbx3 & + & + & - \\
\hline Zfx & - & - & - \\
\hline Ronin & - & - & + \\
\hline Klf4 & + & + & + \\
\hline Nac1 & + & + & + \\
\hline Zfp281 & + & + & + \\
\hline Zic3 & + & + & + \\
\hline Foxo1 & + & - & + \\
\hline Foxd3 & - & + & + \\
\hline Foxp1 & - & + & + \\
\hline Prdm14 & + & + & + \\
\hline Tcf3 & + & + & + \\
\hline Smad1 & - & + & + \\
\hline Stat3 & + & + & + \\
\hline inthis & + & + & + \\
\hline
\end{tabular}

Data in this table is extracted from [26]

Table 1: Pluripotency-associated genes regulated by Oct4, Sox2, and Nanog.

\begin{tabular}{|c|c|c|c|c|}
\hline TFs & Oct4 & Sox2 & Nanog & Ref \\
\hline Sall4 & + & + & + & {$[29,30]$} \\
\hline Dax1 & + & + & + & {$[25]$} \\
\hline Esrrb & + & + & + & {$[26]$} \\
\hline Nr5a2 & + & - & + & {$[56]$} \\
\hline Tbx3 & + & + & - & {$[58]$} \\
\hline Zfx & + & + & + & {$[26]$} \\
\hline Ronin & - & - & - & {$[57]$} \\
\hline Klf4 & + & + & + & {$[25,26,39]$} \\
\hline Nac1 & + & + & + & {$[25]$} \\
\hline Zfp281 & + & + & + & {$[25,45]$} \\
\hline Zic3 & ND & ND & ND & - \\
\hline Fox01 & + & + & ND & {$[48]$} \\
\hline Foxd3 & ND & ND & ND & - \\
\hline Foxp1 & + & - & + & {$[50]$} \\
\hline Prdm14 & + & + & - & {$[47,51]$} \\
\hline Tcf3 & + & + & + & {$[27,54,55]$} \\
\hline Smad1 & + & + & + & {$[26]$} \\
\hline Stat3 & + & + & + & {$[26]$} \\
\hline
\end{tabular}

Table 2: Pluripotency-associated transcription factors regulating Oct4, Sox2, and Nanog genes.

regulation of the core transcriptional circuitry might be important for the disruption of the circuitry during ESC differentiation. Consistently, $Z f p 281$ is dispensable for ESC self-renewal, but is required for proper differentiation of ESCs [44]. Therefore, the expanded transcriptional regulatory network of pluripotency, formed by the core regulatory circuitry and pluripotency-associated transcription factors, ensures the transcriptional profile of ESCs stable enough for self-renewal, but still plastic enough to allow ESC differentiation.

Chromatin immunoprecipitation combined with high-throughput DNA sequencing (ChIP-seq) analysis did not detect Ronin occupancy at the promoters of Nanog, Oct4 and Sox2. Instead, many genes regulated by Ronin are involved in cell metabolism. Therefore, it has been suggested that Ronin contributes to the fast and unimpeded growth of ESCs [57].

Interestingly, the role of FOXP1 in pluripotency maintenance is associated with its alternative splicing. The ESC specific isoform of FOXP1 (FOXP1-ES) differs from other isoforms at the exon 18 (human) or the exon 16 (mouse), which changes the DNA-binding preferences of FOXP1. Therefore, only FOXP1-ES activates pluripotency genes, including OCT4, NANOG and NR5A2, and represses genes involved in differentiation. Consistently, FOXP1-ES, but not FOXP1, promotes ESC self-renewal [50].

There are some conflicting data regarding Prdm14 in mouse ESCs. Chia et al [47] identified PRDM14 as a regulator of OCT4 expression in human ESCs. They also demonstrated that knockdown of Prdm14 in mouse ESCs has no effect on the expression of Oct4 and Sox2. Moreover, $\operatorname{Prdm} 14$ expression level is extremely low in mouse epiblast stem cells (epiSCs), which is considered as the mouse counterpart of human ESCs. These data suggested that Prdm14 is essential for the maintenance of human ESCs, but not for mouse ESCs or epiSCs [47]. In contrast, $\mathrm{Ma}$ et al showed that knockdown of Prdm14 in mouse ESCs not only reduces the expression of Nanog and Sox2, but also induces 
extraembryonic endodermal differentiation. Notably, in the second study, a substantial fraction of $\operatorname{Prdm} 14$ knockdown cells maintains ESC colony morphology and Nanog expression, while other cells differentiate into the extraembryonic endodermal lineage [51]. This phenotype might be explained by either heterogenous knockdown efficiency of Prdm14 or inherent heterogeneity of mouse ESCs. Given that no phenotype was observed upon Prdm14 knockdown in mouse ESCs in the first study, it is more likely that the discrepancy between these two studies is due to differential knockdown efficiency of $\operatorname{Prdm} 14$.

Moreover, many of these pluripotency-associated transcription factors interact with Nanog, Oct4 and/or Sox2 proteins (Table 3) $[31,59,60]$. It has been demonstrated that Dax1 inhibits the transcriptional activity of Oct 4 through its association with Oct4 protein [32]. Together with Nr5a2, Dax1 also activates the expression of Oct4 gene [34]. It appears that Daxl plays a dual role in regulating the transcriptional activity of Oct4. Consistently, either knockdown or over-expression of Dax1 causes ESC differentiation [32,33]. Oct4 also interacts with Foxd3, and inhibits Foxd 3 to activate endodermal genes FoxA1 and FoxA2 [61]. It is not completely understood how other interactions among these pluripotency transcription factors affect their transcriptional activities, and contribute to pluripotency maintenance. Further studies are required to characterize the biological functions of these interactions.

\section{Pluripotency-associated Transcriptional Co-factors}

To regulate gene expression, transcription factors usually recruit other protein factors, which do not bind to DNA by themselves. These factors are named transcriptional co-factors. According to their effects on gene expression, they are categorized into two groups, co-activators and co-repressors. So far, some transcriptional co-factors, such as mediator, cohesin, Cnot, Trim28, Paf1 and the XPC-RAD23B-CETN2 (XPC) nucleotide excision repair complex, have been implicated in ESC self-renewal and pluripotency maintenance [62-65].

Mediator and cohesin were identified in an shRNA screen for factors regulating Oct4 expression in ESCs. Further investigation revealed that mediator and cohesin, as well as the cohesin loading factor Nipbl, interact with each other, and co-occupy the enhancer and core promoter regions of actively transcribed genes, including Oct4 and Nanog. Moreover, mediator and cohesin promote the formation of enhancer-promoter DNA looping, which is required for gene activation [62]. Cnot and Trim28 are transcriptional co-repressors, whose down-regulation leads to ESC differentiation $[65,66]$. Cnot and Trim 28 share many downstream target genes with c-Myc and $\mathrm{Zfx}$, indicating that these four factors cooperate together to regulate a unique transcriptional module in ESC self-renewal. Trim 28 also binds to the promoters of Nanog and Sox2, and interacts with Nanog, Rex1

\begin{tabular}{|c|c|c|c|c|}
\hline TFs & Oct4 & Sox2 & Nanog & Ref \\
\hline Sall4 & + & & + & {$[31,60]$} \\
\hline Dax1 & + & & + & {$[31,32,59]$} \\
\hline Esrrb & + & & + & {$[36,59]$} \\
\hline Klf4 & + & & & {$[60]$} \\
\hline Nac1 & + & & + & {$[31,59]$} \\
\hline Zfp281 & + & + & + & {$[31,45]$} \\
\hline Foxd3 & + & & & {$[61]$} \\
\hline
\end{tabular}

Table 3: Interactions between pluripotency-associated transcription factors and Oct4, Sox2, and Nanog. and Dax1 proteins [31,65]. Knockdown of individual component of the Pol II-associating factor 1 complex (Paflc), reduces Oct4 expression level in ESCs and results in ESC differentiation, suggesting an essential role of the whole Paf1c in pluripotency maintenance. Paf1c occupies the promoters of many pluripotency genes, such as Oct4, Sox2 and Nanog. Paf1c might collaborate with the Set 1 complex to methylate H3K4 at the promoters of pluripotency genes and maintain their expression [64] Recently, through an in vitro transcription assay, the XPC nucleotide excision repair complex was identified as a co-factor for Oct4 and Sox 2 to activate Nanog transcription. Moreover, in ESCs, around 70\% of XPC-targeted genes are also bound by Oct 4 and Sox 2 . Given the tight association of XPC with Oct4 and Sox2, it is not surprising that the XPC complex is required for ESC self-renewal and somatic cell reprogramming [63]. In this case, XPC, the protein complex involved in DNA repair, functions as a transcription co-factor for pluripotency maintenance. It is not clear yet whether the DNA repair activity of XPC is also important for pluripotency. Interestingly, an RNA polymerase III subunit POLR3G has been shown to be required for the maintenance of pluripotency in human ESCs [67]. However, it remains unclear how POLR3G contributes to pluripotency maintenance.

\section{Co-operation of Transcriptional Regulation and Epigenetic Regulation}

As the substrate of transcription, chromatin is regulated by various epigenetic modifications and high-order chromatin structure. Using chromatin interaction analysis by paired-end tag (ChIA-PET) sequencing, a CTCF-chromatin interactome map in mouse ESCs has been constructed. This map revealed that CTCF-associated interactions facilitate three-dimensional chromatin organization, clustering genes with coordinated expression, promoting communications between regulatory elements over long distances, and demarcating nuclear laminchromatin interactions [68]. Using the same technique, widespread promoter-centered chromatin interactions were also detected in human cells [69]. These studies provided a three-dimensional chromatin picture to understand transcriptional regulation in ESCs. It is clear that epigenetic regulation plays critical roles in pluripotency. In this review, we only address the interactions and co-operations between transcription factors and epigenetic regulators in ESCs. More detailed information regarding epigenetic regulators in pluripotency can be found in other reviews $[4,5,70]$.

Through affinity purification followed by mass spectrometry, the binding partners of Oct4 and Nanog have been systematically identified. Indeed, Oct4 and Nanog interact with many chromatin regulators, including the histone deacetylase $\mathrm{NuRD}$, the polycomb repression complex 1 (PRC1), the Lsd1 histone demethylase complex, Wdr5 and the chromatin remodeling complexes Chd1, ISWI, SWI/ SNF, INO80 and Trrap/p400, as well as the DNA methyltransferases Dnmt3a and Dnmt31 [31,59,60,71]. Among these binding partners of Oct4 and Nanog, Chd1 has been shown to be essential for maintaining the open chromatin in ESCs [72]. The chromatin remodeling complexes INO80 and Trrap/p400 are also required for pluripotency maintenance $[47,66]$. Moreover, Oct4 interacts with the histone $\mathrm{H} 3$ lysine 9 (H3K9) methyltransferase Setdb1 (also known as Eset) to repress the trophoblast-associated genes $C d x 2$ and Tcfap2a [73,74]. Wdr5, a core member of the Trithorax $(\operatorname{tr} x G)$ complex, which catalyzes the methylation of H3K4, is required for ESC self-renewal, as well as efficient somatic cell reprogramming. Through interaction with Oct4, Wdr 5 co-occupies many Oct 4 target genes. Further analysis suggested that Wdr5 cooperates with Oct4, Nanog and Sox 2 to activate genes required for ESC self-renewal [75]. However, the exact role of the 
interactions between other chromatin regulators and Oct4/Nanog in pluripotency maintenance remains to be explored.

In addition to the physical interactions between pluripotency transcription factors and chromatin regulators, pluripotency transcription factors also regulate the expression of chromatin regulators. For example, Oct4 binds to genes encoding subunits of the NuRD complex (Mta2, Mbd3, Mta3 and Hdac2), the SWI/SNF complex (Baf155), the PRC1 complex (Phcland Rybp) and the LSD1 complex (Rcor2) [25,26,59]. Chd1 gene is occupied by multiple pluripotency transcription factors, including Nanog, Oct4, Sox2, Smad1 and Zfx [26,72]. Conversely, chromatin regulators also participate in regulating the expression of pluripotency genes. The $\mathrm{H} 3 \mathrm{~K} 9$ demethylase Jmjd2c, whose expression is positively regulated by Oct4, catalyzes the demethylation of $\mathrm{H} 3 \mathrm{~K} 9 \mathrm{Me} 3$ at the Nanog promoter, and maintains the expression of Nanog [76]. Coactivator-associated arginine methyltransferase 1 (Carm1), an essential factor for the self-renewal and pluripotency of ESCs, binds to the promoter of Oct4 and Sox2, and promotes the methylation of histone $\mathrm{H} 3$ arginine 17 and 26 [77].

Non-coding RNAs, including microRNAs and large intergenic non-coding RNAs (lincRNAs), are also important epigenetic regulators for pluripotency maintenance [70,78]. Similar to other genes encoding proteins, many genes encoding microRNAs and lincRNAs are also regulated by Oct4, Sox 2 and Nanog in ESCs [27,78]. MicroRNAs appears to be critical to suppress pluripotency genes upon ESC differentiation. It has been demonstrated that miR-134, miR-296 and miR-470 suppress the expression of Nanog, Oct4 and Sox2 [79]. Consistently, knockout of DGCR8, an RNA-binding protein that assists the RNase III enzyme Drosha in the processing of miRNA, causes differentiation deficiency of ESCs [80]. The important role of lincRNAs in pluripotent cells has been demonstrated by loss-function assay, as well as somatic cell reprogramming [78,81]. How lincRNAs regulate gene expression is not completely understood. One mechanism is that lincRNAs work in cis to regulate neighboring genes. Alternatively, lincRNA transcripts bind to chromatin regulatory proteins, such as Prc1, Cbx1, Cbx3, Tip60/P400, Prc2, Setd8, Eset, Suv39h1, Jarid1b, Jarid1c and Hdac1, thus regulating gene expression [78].

\section{Integration of External Signals into Transcriptional Activity}

In responses to various environmental cues, ESCs either self-renew or differentiate into different cell lineages. Thus, ESCs should be able to sense extracellular signals and transduce the signals into the nucleus to regulate the transcriptional profile accordingly. LIF is widely used in mouse ESC culture medium to maintain ESCs at an undifferentiated state. Bone morphogenetic proteins (BMPs) synergizes with LIF to maintain the pluripotent state of ESCs [52]. In addition, it has been shown that the Wnt pathway also promotes ESC self-renewal [82]. Transcription factors Stat3, Smad proteins and $\beta$-catenin/Tcf3, are downstream effectors for the LIF, BMP, and Wnt pathways, respectively. Interestingly, genome-wide binding site mapping of Stat3, Smad1 and Tcf3 revealed that all three factors occupy the promoters of the core pluripotency genes Oct4, Sox2 and Nanog. Furthermore, Stat3, Smad1 and Tcf 3 bind to many genes co-occupied by Oct4, Sox 2 and Nanog $[26,27,54,55]$. Therefore, the LIF, BMP and Wnt pathways not only directly regulate the expression of the core pluripotency genes, but also co-operate with these core pluripotency factors to activate genes required for pluripotency maintenance and to repress genes involved in differentiation. Simultaneous inhibition of Mek/Erk and GSK3 can maintain ESCs in the pluripotent state independent of LIF [83].
Inhibition of GSK3 stabilizes $\beta$-catenin to facilitate the maintenance of pluripotency [37,82]. Recently, it has been demonstrated that Erk1 and Erk2 phosphorylate Klf4, thus suppressing the transcriptional activity of Klf4 [84]. Yet, these data do not exclude the possibility that other downstream targets of the Mek/Erk and GSK3 signaling are involved in pluripotency maintenance. Further studies are necessary to clarify the mechanisms of the Mek/Erk and GSK3 signaling in pluripotency maintenance.

The expanded transcriptional regulatory network of pluripotency and the interaction network of pluripotency factors further facilitate the connection between signaling events and transcriptional regulation of pluripotency. It have been shown that LIF acts through the PI(3) K-Akt and JAK-Stat 3 pathways to activate Tbx3 and Klf4, respectively. Subsequently, Tbx3 and Klf4 positively regulate Nanog and Sox2 to sustain the core transcriptional circuitry for pluripotency [40]. In addition, $\beta$-catenin and Tcf3, the downstream effectors of the Wnt pathway, promote the expression of $\mathrm{Nr} 5 \mathrm{a} 2$ (also known as Lrh-1), which in turn activates pluripotency genes Nanog, Oct4 and Tbx3 [37].

In contrast to mouse ESCs, human ESCs rely on different signaling pathways to maintain pluripotency. The Activin/Nodal and FGF2 signaling are required for pluripotency maintenance in human ESCs [3,85-87]. Smad2/3 downstream of Activin/Nodal can activate Nanog to maintain pluripotency [88]. However, how the FGF2 signaling pathways connect to the transcriptional regulatory network of pluripotency are not well understood.

\section{Pluripotency and X Chromosome Inactivation}

$\mathrm{X}$ chromosome inactivation (XCI) is an intriguing topic related with pluripotency. One X chromosome in each female mammalian cell is inactivated for transcription in order to compensate the X-linked gene dosage between males and females. In the mouse, XCI shows a tight correlation with pluripotency during embryonic development. In the early cleavage stage embryos, the paternal $\mathrm{X}$ chromosome is non-randomly inactivated (a special form of XCI known as the imprinted XCI) [89,90]. When the epiblast lineage is specified in the blastocyst, pluripotency is established; meanwhile, the inactive paternal $\mathrm{X}$ chromosome is reactivated. Two active $\mathrm{X}$ chromosomes (Xa) can be found in each epiblast cell of a female blastocyst and in the corresponding female ESCs. Shortly after implantation, around E5.5, XCI occurs again; meanwhile, the pluripotent epiblast cells start to differentiate and lose the pluripotency. In the second wave of XCI, each female cell independently and randomly chooses one of the two Xs as the inactive $\mathrm{X}(\mathrm{Xi})$. This form of XCI is known as the random XCI. The XCI status of each cell, once established, is clonally maintained in the subsequent cell generations of all but one type of somatic cell, the primordial germ cell (PGC). The specification of PGCs is a process of de-differentiation [91]. The genome in each PGC is epigenetically reprogrammed to be prepared for regeneration of a new life cycle. By applying special culture conditions, PGCs can be readily converted to a pluripotent cell type in culture, called the embryonic germ (EG) cells. It is no coincidence that X reactivation (XCR) occurs during PGC specification. Besides all the embryonic developmental events, $\mathrm{XCI}$ is also tightly linked to pluripotency in vitro. XCI occurs during in vitro differentiation of ESCs; meanwhile XCR is observed when pluripotency is artificially generated in induced pluripotent stem (iPS) cells [92], by nuclear transfer [93] or cell fusion [94]. Besides the mechanistic connection of the regulatory mechanisms of XCI and pluripotency, dosage compensation is also critical for early embryonic development. Embryos with XCI defects are early embryonic lethal [95]. Mutant ESCs with XCI defects could not survive during in vitro differentiation 
[96]. Although the undifferentiated female mouse ESCs, with two active Xs per cell, are pluripotent, these cells are more difficult to be maintained in high quality in culture. The culprit is believed to be the lack of dosage compensation in these cells. Therefore, X-linked gene dosage is essential for pluripotency in females. Furthermore, $\mathrm{XCI}$ is an interesting topic of pluripotency also because the inactivation status of the $\mathrm{X}$ chromosome is arguably the most stringent test available to access the pluripotency in the current human ES cell lines. We will discuss on this in more details in the following paragraphs.

XCI occurs in a female-specific and allele-specific manner, which cannot be achieved by the core regulatory circuitry of pluripotency alone. The tight correlation between pluripotency and XCI must be achieved by pluripotency factors controlling key XCI regulators. The search for the direct connections of pluripotency factors with the key regulatory factors of XCI has started. The chromosome-wide gene silencing of XCI is triggered by an ncRNA, called Xist (Xi specific transcript) [97-99]. The X-linked Xist gene is expressed at low level from both Xs in each undifferentiated female ESC. Upon differentiation, the transcription of Xist is allele-specifically up-regulated along the chosen Xi. The up-regulated Xist RNA transcripts spread and coat the chromosome territory in cis to establish multiple layers of epigenetic modifications along the chromosome. The chromosome-wide gene silencing is then achieved. In RNA FISH, the Xist RNA can be visualized as a cloud signal (the Xist cloud) enveloping the Xi chromosome territory [100]. Interestingly, Nanog expression is correlated with Xist repression during epiblast lineage specification in blastocyst [101]. Over-expression of Nanog accelerates Xist repression during epiblast lineage specification without affecting XCR status [102]. However, Nanog knockout in ESCs only causes minor up-regulation of Xist expression [103]. Different from Nanog, deletion of Oct4 in ESCs caused Xist cloud formation in a small fraction of cells $[103,104]$. Key pluripotency factors have broad effects on ESCs. Therefore, direct manipulation on pluripotency factors may not reveal their direct relation with XCI. It is important to identify the DNA binding site of pluripotency factors along the key genes involved in XCI. Deletion of these DNA binding sites can help to reveal the direct connection of pluripotency factors and XCI. By chromatin immunoprecipitation, one prominent binding site of Oct4, Nanog and Sox 2 was identified within Xist intron 1 [103]. A few other binding sites of Oct 4 and Nanog were also identified within or close to the Xist gene body [104,105]. A binding site of Rex1, cMyc and Klf4 was identified at the 5 ' region of the Tsix gene (an anti-sense RNA of Xist) [106]. Binding sites of Oct4 Sox 2 and Nanog can also be found upstream of the RNF12 gene [26], which encodes an E3 ubiquitin ligase involved in sensing $\mathrm{X}$ chromosome copy number per cell during the initiation of XCI. The binding sites of pluripotency factors within Xist intron 1 have been investigated by a few studies. Knocking out this DNA region did not cause a significant up-regulation of Xist [107]. It is possible that Tsix and pluripotency factors work synergistically to repress Xist expression. Double deletion of the intron 1 binding site and Tsix confirmed this notion [108]. However the double deletion only caused the upregulation of the Xist in a small fraction of cells. It should be noted that the double knockout was carried out on a Xist transgene in male cells. It is worth to repeat the knockout on the endogenous DNA locus and in female cells. It is also important to re-check the binding pattern of the pluripotency factors along the double knockout DNA allele. In addition, pluripotency factors and co-factors are known to be involved in long distance chromatin interactions, for example the promoter and enhancer interaction [62]. It is important to search for the DNA region, which interacts with the Xist/Tsix genes but is located far away from the Xist/Tsix gene body. Furthermore, Oct4, Nanog and Sox2 are all expressed at a similar level to ESCs in a different cell type, the epiblast stem cells (EpiSCs, see the following paragraph for details) $[109,110]$. However, in female EpiSCs, XCI has been established. Therefore, the three key pluripotency factors alone cannot fully explain the Xist repression in ESCs.

Besides its mechanistic connection with pluripotency, XCI is also a unique epigenetic identity, which distinguishes the primed and naïve pluripotency in mouse. The epiblast cells from a post-implantation embryo can be cultured in vitro to establish a cell line called epiblast stem cells $[109,110]$. Oct4, Sox 2 and Nanog are all expressed in EpiSCs at levels comparable to ESCs. EpiSCs can be differentiated into all three germ layers in vitro and form teratoma in the nude mice. Therefore, EpiSCs are pluripotent. Different from ESCs, EpiSCs show different colony morphology, require different culture conditions (FGF), and rely on different intracellular signaling pathways (Activin/Nodal) to maintain pluripotency. In addition, EpiSCs are unable to pass more stringent tests on their pluripotency, for example EpiSCs cannot give germline transmission. Furthermore, in female EpiSCs, XCI already occurs. It has been proposed the pluripotency carried in ESCs is naïve pluripotency, and the pluripotency carried in EpiSCs is primed pluripotency [111]. Since both ESCs and EpiSCs express Oct4, Nanog and Sox2, comparing the gene expression profiles of the two cell types may help to identify new genes critical for naïve pluripotency. It is already known that Klf4 shows a much higher expression level in ESCs than EpiSCs [109]. Forced expression of Klf4 in EpiSCs and switching the culture condition to ESC culture condition could convert the primed pluripotency in EpiSCs to naive pluripotency, in which the $\mathrm{Xi}$ was reactivated [112]. Meanwhile, the same conversion could also be achieved by prolonged culture of post-implantation epiblast cells in ES culture conditions [113]. However both methods showed low conversion efficiency. Comparing the silencing status of Xi in EpiSCs and in somatic cells also generated some interesting findings [114]. The Xi in EpiSCs, which does not carry the enrichment of macroH2A (a histone variant), was still permissive for reactivation after the nucleus of mouse cell was transferred into xenopus germinal vesicles. The macroH2A-enriched $\mathrm{Xi}$ from mouse fibroblast was resistant for reactivation in this experimental system. In summary, the similarity and the difference between ESCs and EpiSCs are interesting topics for pluripotency. The XCI status is one epigenetic signature, which shows the difference between the two types of pluripotency.

All the foregoing knowledge about pluripotency and XCI were generated in mouse studies. Human ESCs (hESCs) are studied less extensively, but are more important for future regenerative medicine. Interestingly, hESCs are similar to mouse EpiSCs in colony morphology, culture conditions, and the required internal signaling pathway to maintain pluripotency $[109,110]$. hESCs can also pass low stringent tests on pluripotency, such as in vitro differentiation and teratoma formation. However, more stringent tests, such as chimera formation, cannot be applied in hESC studies due to the ethical concerns. It is an enormous concern that the current hESC lines may resemble the primed pluripotency in mouse. Indeed, XCI has occurred in many hESC lines [115]. Some of the cell lines even showed an inactive X chromosome missing the Xist RNA coating. hESC lines with two Xa per cell are available, but maintaining such cell lines in culture requires scrupulous care. Similar to hESCs, different XCI status in human iPS cells has been observed. Some groups reported that Xi was retained in female human iPS cells [116-118], while others reported partial XCR [119,120]. These observations clearly show that the culture conditions need to be further improved to maintain hESCs in culture more stably. Many further believe that naïve hESC lines can be achieved by improved culture conditions. 
Indeed, culturing the cells under physiological oxygen level [121], in altered culture medium [122] and by forced gene expression [123] help to establish female hESC lines with two Xa per cell. Similar to hESCs and human iPS cells, different observations on the XCI status have been made on human pre-implantation embryos. A recent study on the preimplantation human embryos observed the onset of XCI dramatically different from the one in mouse [124]. Xist cloud formation was observed in the ICM on all the X alleles (the male X, and the two female $\mathrm{Xs}$ ); and Xist up-regulation did not trigger gene silencing. Interestingly, a different observation on the onset of XCI in human embryos was made in a separate study [125]. One possible explanation on these different observations is that the current techniques of in vitro handling human pre-implantation embryos needs to be further optimized. On the other hand, whether the naïve pluripotency can be harvested from human embryos in culture is still a concern [111]. The egg cylinder, an embryonic structure where the EpiSCs are isolated, and the diapause, a phenomenon in which the development of a blastocyst is "paused" in the uterus for a later implantation, may explain why naïve pluripotency can be stably harvested from mouse embryos. However, egg cylinder and diapause are specific to rodents. The embryonic development programs of other mammals, such as the human, may not be permissive for a stable harvest on the naïve pluripotency. In summary, whether hESC lines with naïve pluripotency can be harvested or stably preserved in culture conditions is a pressing and challenging issue. The functional criteria, such as chimera formation and germ line transmission, which can be used to distinguish the primed and naïve pluripotency in mouse cannot be applied to human cells due to moral concerns. XCI is a unique epigenetic identity, which may help to distinguish the primed and naïve pluripotency in hESCs.

\section{Transcription Factors in Reprogramming}

By expression of several defined factors, differentiated cells can be reprogrammed into a pluripotent state, namely induced pluripotent stem cells. Many of these reprogramming factors are indeed core pluripotency or pluripotency-associated transcription factors. The most widely used Yamanaka factors are Oct4, Sox2, Klf4 and c-Myc, and Yu et al. [9] used OCT4, SOX2, NANOG and LIN28 to reprogram human fibroblasts $[7,9]$. To reprogram somatic cells to the pluripotent state, these exogenous reprogramming factors might activate the endogenous core transcriptional circuitry for pluripotency, as well as the expanded transcriptional regulatory network of pluripotency, eventually remodeling the transcriptional profiles. Comparing the expression profiles of partially reprogrammed cells and iPS/ES cells, transcriptional regulators are not sufficiently activated in partially reprogrammed cells, further demonstrating the importance of the transcriptional regulatory network in the establishment and maintenance of pluripotency. It have been shown that the genome-wide binding profiles of the four Yamanaka factors have significant overlap in iPS and ES cells, but not in partially reprogrammed cells. In partially reprogrammed cells, the binding of Oct4, Sox 2 and Klf4 to their targets is more severely compromised than the binding of c-Myc. It is possible that other factors which are absent in partially reprogrammed cells, such as Nanog, are required for the binding of Oct4, Sox2 and Klf4 to their targets [126].

In search for other reprogramming factors, more pluripotencyassociated transcription factors have been shown to have reprogramming activities. For example, iPS cells can be derived from mouse embryonic fibroblasts (MEFs) with Esrrb, Oct4 and Sox2 [127]. $\mathrm{Nr} 5 \mathrm{a} 2$ can reprogram MEFs with Sox2 and Klf4, without the need of Oct4 or c-Myc [56]. Tbx3, together with Oct4, Sox2 and Klf4, allows the derivation of iPS cells with improved quality. iPS cells reprogrammed with Tbx 3 contribute to germ cells in the gonad more efficiently than iPS cells derived without $T b x 3$. Consequently, iPS cells reprogrammed with $T b x 3$ show higher germline transmission frequency [58]. PRDM14 also enhances the reprogramming efficiency of human fibroblasts by the four Yamanaka factors [47]. Esrrb, Nr5a2, Tbx3 and PRDM14 all bind to at least two of the Oct4, Sox2 and Nanog promoters (Table 2). Moreover, these four reprogramming factors share large amount of common target genes with Oct4, Sox2 and Nanog $[26,47,51,56,58]$. It has been suggested that occupying by multiple factors is associated with stronger transcriptional activation [126]. Therefore, the reprogramming activities of these pluripotency-associated factors can be explained by their transcriptional activity to activate and maintain the transcriptional regulatory network of pluripotency.

As we discuss in the section of integration of external signals into transcriptional activity, signaling events can be integrated into the transcriptional regulatory network of pluripotency. Thus, through modulating the activities of signaling pathways, the efficiency of somatic cell reprogramming can be improved. Indeed, many chemicals targeting signaling pathways have been demonstrated to promote reprogramming. For example, inhibition of MEK and GSK3 pathways by PD0325901 and CHIR99021 allows completely reprogramming to the ground state of pluripotency from MEF-derived and neural stem cell-derived pre-iPS cell clones [128]. Wnt3a enhances the iPS derivation rate from MEFs by Oct4, Sox2 and Klf4 by around 20-fold [129]. An inhibitor of TGF- $\beta$ signaling, RepSox (also named E-616452), allows derivation of iPS cells with Oct4, Klf4 and c-Myc, in the absence of Sox2. One possible mechanism of RepSox to facilitate reprogramming is to activate Nanog expression [130]. Moreover, simultaneous inhibition of MEK, GSK3 and TGF- $\beta$ signaling by PD0325901, CHIR99021 and A-83-01, has been applied in the derivation of rat and human iPS cells, which resemble mouse ESCs [131].

\section{Summary}

It becomes clear that transcriptional regulation plays a pivot role in pluripotency maintenance. Illustrated in Figure 1, Oct4, Sox 2 and Nanog form the core transcriptional regulatory circuitry for pluripotency [2327]. Through regulating the expression of Oct4, Sox 2 and Nanog, some pluripotency-associated transcription factors, including Sall4, Esrrb, Nr5a2, Tbx3, Zfx, Klf4, Foxo1, Foxp1, Prdm14 and Nac1, stabilize the core transcriptional regulatory circuitry $[25,26,39,47,51,56,58]$ Other pluripotency-associated transcription factors, such as Dax1 and Zfp281, negatively regulate the expression or the transcriptional activity of core pluripotency factors, thus facilitating the destruction of the core transcriptional regulatory circuitry during differentiation $[25,32,44,45]$. In addition to the transcriptional regulatory network among the core transcriptional regulatory circuitry and pluripotencyassociated transcription factors, the physical interactions of these transcription factors, as well as transcriptional co-factors, build up another regulatory network for pluripotency $[31,59,60]$. Moreover, epigenetic regulators cooperate with transcription factors to maintain the unique transcriptional profiles of ESCs. Meanwhile, the pluripotency status is connected with and further stabilized by external signals, so the pluripotent cells are able to respond to environmental cues to initiate proper differentiation program [52-55].

Despite the fast accumulating data of transcriptional regulation in ESCs, there are many important questions to be answered. Why do ESCs apply such a complicated network to regulate the expression of Oct4, Sox2 and Nanog? How is the expanded transcriptional regulatory network of pluripotency disrupted during ESC differentiation? How do external signals direct ESC differentiation? Ultimately, our 
Citation: Chen L, Zhang LF (2012) A Balanced Network: Transcriptional Regulation in Pluripotent Stem Cells. J Stem Cell Res Ther S10:004. doi:10.4172/2157-7633.S10-004

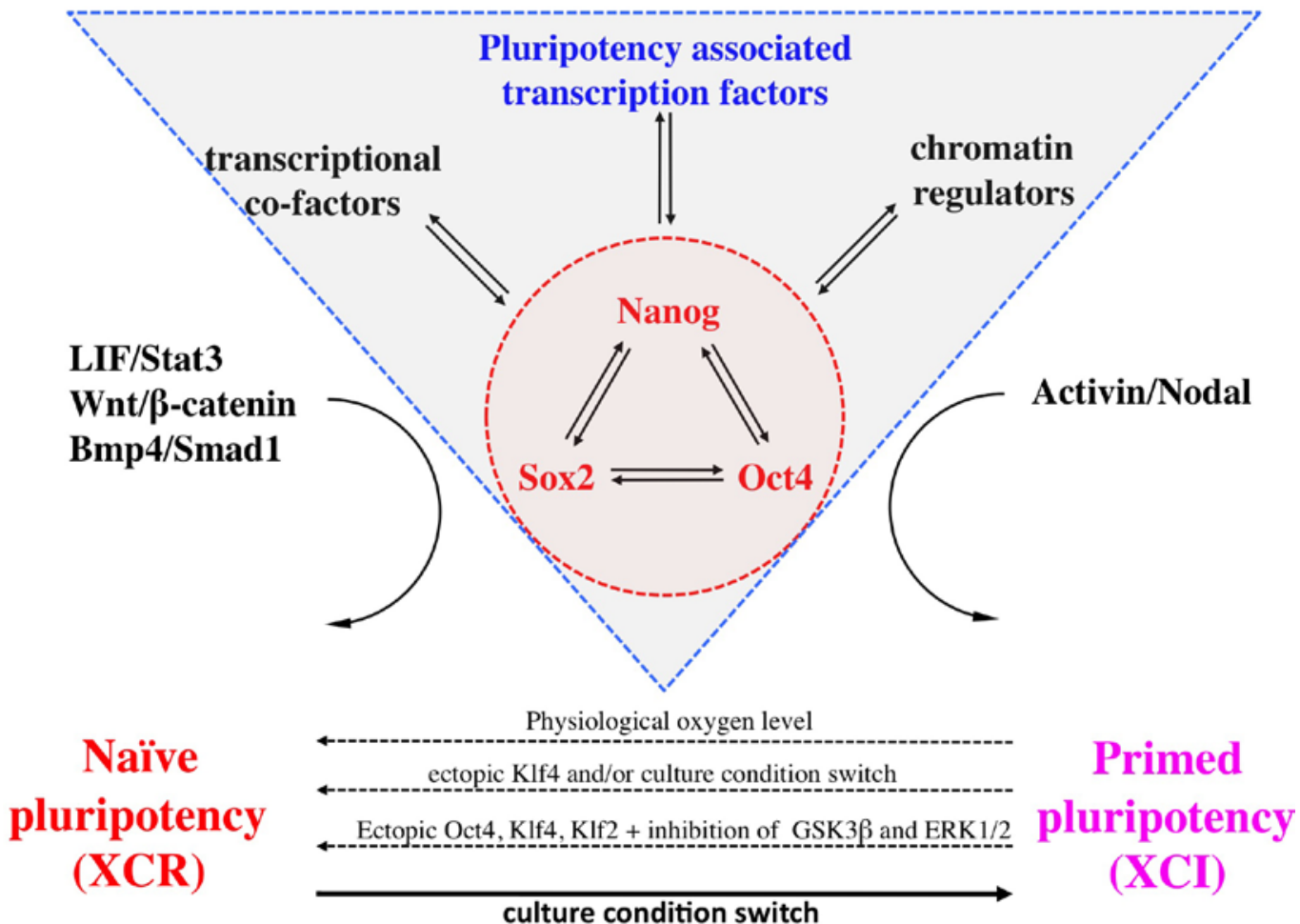

Figure 1: Schematic illustration of pluripotency maintenance by transcriptional regulation, epigenetic regulation, and signaling pathways. Oct4, Sox2 and Nanog form the core transcriptional regulatory circuitry for pluripotency (highlighted with a red circle). Pluripotency-associated transcription factors, together with the core transcriptional regulatory circuitry, form the expanded transcriptional regulatory network of pluripotency. Transcriptional co-factors and chromatin regulators collaborate with transcription factors to maintain pluripotency. Different signaling events facilitate the maintenance of the naïve or primed pluripotency.

understanding of transcriptional regulation in ESCs should be applied to further improve derivation of novel pluripotent stem cells, as well as directed differentiation of ESCs into desired cell types.

\section{Acknowledgement}

This work was supported by grants from the National Natural Science Foundation of China (No. 90919009), the National Basic Research Program of China (No. 2009CB941000 and No.2010CB833603), the transgenic program, the Ministry of Agriculture of China (No. 2009ZX08006-010B and No. 2009ZX08006011B) and the Singapore Stem Cell Consortium (SSCC/09/015).

\section{References}

1 Evans MJ, Kaufman MH (1981) Establishment in culture of pluripotential cells from mouse embryos. Nature 292: 154-156.

2 Martin GR (1981) Isolation of a pluripotent cell line from early mouse embryos cultured in medium conditioned by teratocarcinoma stem cells. Proc Natl Acad Sci USA 78: 7634-7638.

3 Thomson JA, Itskovitz-Eldor J, Shapiro SS, Waknitz MA, Swiergiel JJ, et al (1998) Embryonic stem cell lines derived from human blastocysts. Science 282: 1145-1147.

4 Young RA (2011) Control of the embryonic stem cell state. Cell 144: 940-954

5 Bibikova M, Laurent LC, Ren B, Loring JF, Fan JB (2008) Unraveling epigenetic regulation in embryonic stem cells. Cell Stem Cell 2: 123-134.

6 Chen L, Daley GQ (2008) Molecular basis of pluripotency. Hum Mol Genet 17 R23-R27.

7 Takahashi K, Yamanaka S (2006) Induction of pluripotent stem cells from mouse embryonic and adult fibroblast cultures by defined factors. Cell 126: 663-676

8 Takahashi K, Tanabe K, Ohnuki M, Narita M, Ichisaka T, et al. (2007) Induction of Pluripotent Stem Cells from Adult Human Fibroblasts by Defined Factors. Cell 131: 861-872.
9 Yu J, Vodyanik MA, Smuga-Otto K, Antosiewicz-Bourget J, Frane JL, et al. (2007) Induced Pluripotent Stem Cell Lines Derived from Human Somatic Cells. Science 318: 1917-1920

10 Chambers I, Colby D, Robertson M, Nichols J, Lee S, et al. (2003) Functional expression cloning of Nanog, a pluripotency sustaining factor in embryonic stem cells. Cell 113: 643-655.

11 Nichols J, Zevnik B, Anastassiadis K, Niwa H, Klewe-Nebenius D, et al. (1998) Formation of pluripotent stem cells in the mammalian embryo depends on the POU transcription factor Oct4. Cell 95: 379-391.

12 Mitsui K, Tokuzawa Y, Itoh H, Segawa K, Murakami M, et al. (2003) The homeoprotein Nanog is required for maintenance of pluripotency in mouse epiblast and ES cells. Cell 113: 631-642.

13 Avilion AA, Nicolis SK, Pevny LH, Perez L, Vivian N, et al. (2003) Multipotent cell lineages in early mouse development depend on SOX2 function. Genes Dev 17: 126-140.

14 Botquin V, Hess H, Fuhrmann G, Anastassiadis C, Gross MK, et al. (1998) New POU dimer configuration mediates antagonistic control of an osteopontin preimplantation enhancer by Oct-4 and Sox-2. Genes Dev 12: 2073-2090.

15 Nishimoto M, Fukushima A, Okuda A, Muramatsu M (1999) The gene for the embryonic stem cell coactivator UTF1 carries a regulatory element which selectively interacts with a complex composed of Oct-3/4 and Sox-2. Mol Cell Biol 19: 5453-5465.

16 Yuan H, Corbi N, Basilico C, Dailey L (1995) Developmental-specific activity of the FGF-4 enhancer requires the synergistic action of Sox2 and Oct-3. Genes Dev 9: 2635-2645

17 Niwa H, Miyazaki J, Smith AG (2000) Quantitative expression of Oct-3/4 defines differentiation, dedifferentiation or self-renewal of ES cells. Nat Genet 24: 372-376.

18 Fong H, Hohenstein KA, Donovan PJ (2008) Regulation of self-renewal and pluripotency by Sox2 in human embryonic stem cells. Stem Cells 26: 1931 1938. 
Citation: Chen L, Zhang LF (2012) A Balanced Network: Transcriptional Regulation in Pluripotent Stem Cells. J Stem Cell Res Ther S10:004. doi:10.4172/2157-7633.S10-004

19 Li J, Pan G, Cui K, Liu Y, Xu S, et al. (2007)A dominant-negative form of mouse SOX2 induces trophectoderm differentiation and progressive polyploidy in mouse embryonic stem cells. J Biol Chem 282: 19481-19492.

20 Hyslop L, Stojkovic M, Armstrong L, Walter T, Stojkovic P, et al. (2005) Downregulation of NANOG induces differentiation of human embryonic stem cells to extraembryonic lineages. Stem Cells 23: 1035-1043.

21 Hough SR, Clements I, Welch PJ, Wiederholt KA (2006) Differentiation of mouse embryonic stem cells after RNA interference-mediated silencing of OCT4 and Nanog. Stem Cells 24: 1467-1475.

22 Chambers I, Silva J, Colby D, Nichols J, Nijmeijer B, et al. (2007) Nanog safeguards pluripotency and mediates germline development. Nature 450: 1230-1234.

23 Boyer LA, Lee TI, Cole MF, Johnstone SE, Levine SS, et al. (2005) Core transcriptional regulatory circuitry in human embryonic stem cells. Cell 122: 947-956.

24 Loh YH, Wu Q, Chew JL, Vega VB, Zhang W, et al. (2006) The Oct4 and Nanog transcription network regulates pluripotency in mouse embryonic stem cells. Nat Genet 38: 431-440.

25 Kim J, Chu J, Shen X, Wang J, Orkin SH (2008) An extended transcriptional network for pluripotency of embryonic stem cells. Cell 132: 1049-1061.

26 Chen X, Xu H, Yuan P, Fang F, Huss M, et al. (2008) Integration of external signaling pathways with the core transcriptional network in embryonic stem cells. Cell 133: 1106-1117.

27 Marson A, Levine SS, Cole MF, Frampton GM, Brambrink T, et al. (2008) Connecting microRNA genes to the core transcriptional regulatory circuitry of embryonic stem cells. Cell 134: 521-533.

28 Thomson M, Liu SJ, Zou LN, Smith Z, Meissner A, et al. (2011) Pluripotency factors in embryonic stem cells regulate differentiation into germ layers. Cell 145: 875-889.

29 Wu Q, Chen X, Zhang J, Loh YH, Low TY, et al. (2006) Sall4 Interacts with Nanog and Co-occupies Nanog Genomic Sites in Embryonic Stem Cells. J Biol Chem 281: 24090-24094.

30 Zhang J, Tam WL, Tong GQ, Wu Q, Chan HY, et al. (2006) Sall4 modulates embryonic stem cell pluripotency and early embryonic development by the transcriptional regulation of Pou5f1. Nat Cell Biol 8: 1114-1123.

31 Wang J, Rao S, Chu J, Shen X, Levasseur DN, et al. (2006) A protein interaction network for pluripotency of embryonic stem cells. Nature 444: 364-368.

32 Sun C, Nakatake Y, Akagi T, Ura H, Matsuda T, et al. (2009) Dax1 binds to Oct $3 / 4$ and inhibits its transcriptional activity in embryonic stem cells. Mol Cell Biol 29: 4574-4583.

33 Khalfallah O, Rouleau M, Barbry P, Bardoni B, Lalli E (2009) Dax-1 knockdown in mouse embryonic stem cells induces loss of pluripotency and multilineage differentiation. Stem Cells 27: 1529-1537.

34 Kelly VR, Xu B, Kuick R, Koenig RJ, Hammer GD (2010) Dax1 up-regulates Oct4 expression in mouse embryonic stem cells via LRH-1 and SRA. Mol Endocrinol 24: 2281-2291.

35 Ivanova N, Dobrin R, Lu R, Kotenko I, Levorse J, et al. (2006) Dissecting selfrenewal in stem cells with RNA interference. Nature 442: 533-538.

36 Zhang X, Zhang J, Wang T, Esteban MA, Pei D (2008) Esrrb activates Oct4 transcription and sustains self-renewal and pluripotency in embryonic stem cells. J Biol Chem 283: 35825-35833.

37 Wagner RT, Xu X, Yi F, Merrill BJ, Cooney AJ (2010) Canonical Wnt/betacatenin regulation of liver receptor homolog-1 mediates pluripotency gene expression. Stem Cells 28: 1794-1804.

38 Galan-Caridad JM, Harel S, Arenzana TL, Hou ZE, Doetsch FK, et al. (2007) $\mathrm{Zfx}$ controls the self-renewal of embryonic and hematopoietic stem cells. Cell 129: 345-357.

39 Jiang J, Chan YS, Loh YH, Cai J, Tong GQ, et al. (2008) A core Klf circuitry regulates self-renewal of embryonic stem cells. Nat Cell Biol 10: 353-360.

40 Niwa H, Ogawa K, Shimosato D, Adachi K (2009) A parallel circuit of LIF signalling pathways maintains pluripotency of mouse ES cells. Nature 460: 118-122.
41 Lu R, Yang A, Jin Y (2011) Dual functions of T-box 3 (Tbx3) in the control of self-renewal and extraembryonic endoderm differentiation in mouse embryonic stem cells. J Biol Chem 286: 8425-8436.

42 Dejosez M, Krumenacker JS, Zitur LJ, Passeri M, Chu LF, et al. (2008) Ronin is essential for embryogenesis and the pluripotency of mouse embryonic stem cells. Cell 133: 1162-1174.

43 Lim LS, Loh YH, Zhang W, Li Y, Chen X, et al. (2007) Zic3 is required fo maintenance of pluripotency in embryonic stem cells. Mol Biol Cell 18: 13481358.

44 Fidalgo M, Shekar PC, Ang YS, Fujiwara Y, Orkin SH, et al. (2011) Zfp281 functions as a transcriptional repressor for pluripotency of mouse embryonic stem cells. Stem Cells 29: 1705-1716.

45 Wang ZX, Teh CH, Chan CM, Chu C, Rossbach M, et al. (2008) The transcription factor Zfp281 controls embryonic stem cell pluripotency by direct activation and repression of target genes. Stem Cells 26: 2791-2799.

46 Liu Y, Labosky PA (2008) Regulation of embryonic stem cell self-renewal and pluripotency by Foxd3. Stem Cells 26: 2475-2484.

47 Chia NY, Chan YS, Feng B, Lu X, Orlov YL, et al. (2010) A genome-wide RNA screen reveals determinants of human embryonic stem cell identity. Nature 468: 316-320.

48 Zhang X, Yalcin S, Lee DF, Yeh TY, Lee SM, et al. (2011) FOXO1 is an essentia regulator of pluripotency in human embryonic stem cells. Nat Cell Biol 13 1092-1099.

49 Hanna LA, Foreman RK, Tarasenko IA, Kessler DS, Labosky PA (2002) Requirement for Foxd3 in maintaining pluripotent cells of the early mouse embryo. Genes Dev 16: 2650-2661.

50 Gabut M, Samavarchi-Tehrani P, Wang X, Slobodeniuc V, O'Hanlon D, et al. (2011) An alternative splicing switch regulates embryonic stem cell pluripotency and reprogramming. Cell 147: 132-146.

51 Ma Z, Swigut T, Valouev A, Rada-Iglesias A, Wysocka J (2011) Sequencespecific regulator Prdm14 safeguards mouse ESCs from entering extraembryonic endoderm fates. Nat Struct Mol Biol 18: 120-127.

52 Ying QL, Nichols J, Chambers I, Smith A (2003) BMP induction of Id proteins suppresses differentiation and sustains embryonic stem cell self-renewal in collaboration with STAT3. Cell 115: 281-292.

53 Niwa H, Burdon T, Chambers I, Smith A (1998) Self-renewal of pluripoten embryonic stem cells is mediated via activation of STAT3. Genes Dev 12: 2048 2060.

54 Cole MF, Johnstone SE, Newman JJ, Kagey MH, Young RA (2008) Tcf3 is an integral component of the core regulatory circuitry of embryonic stem cells Genes Dev 22: 746-755

55 Tam WL, Lim CY, Han J, Zhang J, Ang YS, et al. (2008) T-cell factor 3 regulates embryonic stem cell pluripotency and self-renewal by the transcriptional contro of multiple lineage pathways. Stem Cells 26: 2019-2031.

56 Heng JC, Feng B, Han J, Jiang J, Kraus P, et al. (2010) The nuclear receptor $\mathrm{Nr} 5 \mathrm{a} 2$ can replace Oct4 in the reprogramming of murine somatic cells to pluripotent cells. Cell Stem Cell 6: 167-174.

57 Dejosez M, Levine SS, Frampton GM, Whyte WA, Stratton SA, et al. (2010) Ronin/Hcf-1 binds to a hyperconserved enhancer element and regulates genes involved in the growth of embryonic stem cells. Genes Dev 24: 1479-1484.

58 Han J, Yuan P, Yang H, Zhang J, Soh BS, et al. (2010) Tbx3 improves the germline competency of induced pluripotent stem cells. Nature 463: 1096-1100.

59 van den Berg DL, Snoek T, Mullin NP, Yates A, Bezstarosti K, et al. (2010) An Oct4-centered protein interaction network in embryonic stem cells. Cell Stem Cell 6: 369-381.

60 Pardo M, Lang B, Yu L, Prosser H, Bradley A, et al. (2010) An expanded Oct4 interaction network: implications for stem cell biology, development, and disease. Cell Stem Cell 6: 382-395

61 Guo Y, Costa R, Ramsey H, Starnes T, Vance G, et al. (2002) The embryonic stem cell transcription factors Oct-4 and FoxD3 interact to regulate endodermalspecific promoter expression. Proc Natl Acad Sci USA 99: 3663-3667. 
Citation: Chen L, Zhang LF (2012) A Balanced Network: Transcriptional Regulation in Pluripotent Stem Cells. J Stem Cell Res Ther S10:004. doi:10.4172/2157-7633.S10-004

62 Kagey MH, Newman JJ, Bilodeau S, Zhan Y, Orlando DA, et al. (2010) Mediator and cohesin connect gene expression and chromatin architecture. Nature 467: 430-435

63 Fong YW, Inouye C, Yamaguchi T, Cattoglio C, Grubisic I, et al. (2011) A DNA repair complex functions as an Oct4/Sox2 coactivator in embryonic stem cells. Cell 147: 120-131.

64 Ding L, Paszkowski-Rogacz M, Nitzsche A, Slabicki MM, Heninger AK, et al. (2009) A genome-scale RNAi screen for Oct4 modulators defines a role of the Paf1 complex for embryonic stem cell identity. Cell Stem Cell 4: 403-415.

65 Hu G, Kim J, Xu Q, Leng Y, Orkin SH, et al. (2009) A genome-wide RNAi screen identifies a new transcriptional module required for self-renewal. Genes Dev 23: 837-848.

66 Fazzio TG, Huff JT, Panning B (2008) An RNAi screen of chromatin proteins identifies Tip60-p400 as a regulator of embryonic stem cell identity. Cell 134: $162-174$

67 Wong RC, Pollan S, Fong H, Ibrahim A, Smith EL, et al. (2011) A novel role for an RNA polymerase III subunit POLR3G in regulating pluripotency in human embryonic stem cells. Stem Cells 29: 1517-1527.

68 Handoko L, Xu H, Li G, Ngan CY, Chew E, et al. (2011) CTCF-mediated functional chromatin interactome in pluripotent cells. Nat Genet 43: 630-638.

69 Li G, Ruan X, Auerbach RK, Sandhu KS, Zheng M, et al. (2012) Extensive promoter-centered chromatin interactions provide a topological basis for transcription regulation. Cell 148: 84-98.

70 Tiscornia G, Izpisua Belmonte JC (2010) MicroRNAs in embryonic stem cell function and fate. Genes Dev 24: 2732-2741.

71 Ding J, Xu H, Faiola F, Ma'ayan A, Wang J (2012) Oct4 links multiple epigenetic pathways to the pluripotency network. Cell Res 22: 155-167

72 Gaspar-Maia A, Alajem A, Polesso F, Sridharan R, Mason MJ, et al. (2009) Chd1 regulates open chromatin and pluripotency of embryonic stem cells. Nature 460: 863-868.

73 Yeap LS, Hayashi K, Surani MA (2009) ERG-associated protein with SET domain (ESET)-Oct4 interaction regulates pluripotency and represses the trophectoderm lineage. Epigenetics Chromatin 2: 12

74 Yuan P, Han J, Guo G, Orlov YL, Huss M, et al. (2009) Eset partners with Oct4 to restrict extraembryonic trophoblast lineage potential in embryonic stem cells. Genes Dev 23: 2507-2520.

75 Ang YS, Tsai SY, Lee DF, Monk J, Su J, et al. (2011) Wdr5 Mediates SelfRenewal and Reprogramming via the Embryonic Stem Cell Core Transcriptional Network. Cell 145: 183-197.

76 Loh YH, Zhang W, Chen X, George J, Ng HH (2007) Jmjd1a and Jmjd2C histone H3 Lys 9 demethylases regulate self-renewal in embryonic stem cells. Genes Dev 21: 2545-2557.

77 Wu Q, Bruce AW, Jedrusik A, Ellis PD, Andrews RM, et al. (2009) CARM1 is required in embryonic stem cells to maintain pluripotency and resist differentiation. Stem Cells 27: 2637-2645.

78 Guttman M, Donaghey J, Carey BW, Garber M, Grenier JK, et al. (2011) lincRNAs act in the circuitry controlling pluripotency and differentiation. Nature 477: 295-300.

79 Tay Y, Zhang J, Thomson AM, Lim B, Rigoutsos I (2008) MicroRNAs to Nanog Oct4 and Sox2 coding regions modulate embryonic stem cell differentiation. Nature 455: 1124-1128.

80 Wang Y, Medvid R, Melton C, Jaenisch R, Blelloch R (2007) DGCR8 is essential for microRNA biogenesis and silencing of embryonic stem cell self-renewal. Nat Genet 39: 380-385.

81 Loewer S, Cabili MN, Guttman M, Loh YH, Thomas K, et al. (2010) Large intergenic non-coding RNA-RoR modulates reprogramming of human induced pluripotent stem cells. Nat Genet 42: 1113-1117.

82 Sato N, Meijer L, Skaltsounis L, Greengard P, Brivanlou AH (2004) Maintenance of pluripotency in human and mouse embryonic stem cells through activation of Wnt signaling by a pharmacological GSK-3-specific inhibitor. Nat Med 10: $55-63$

83 Ying QL, Wray J, Nichols J, Batlle-Morera L, Doble B, et al. (2008) The ground state of embryonic stem cell self-renewal. Nature 453: 519-523.
$84 \mathrm{Kim} \mathrm{MO}$, Kim SH, Cho YY, Nadas J, Jeong CH, et al. (2012) ERK1 and ERK2 regulate embryonic stem cell self-renewal through phosphorylation of KIf4. Nat Struct Mol Biol 19: 283-290.

85 Beattie GM, Lopez AD, Bucay N, Hinton A, Firpo MT, et al. (2005) Activin a maintains pluripotency of human embryonic stem cells in the absence of feeder layers. Stem Cells 23: 489-495

86 Vallier L, Alexander M, Pedersen RA (2005) Activin/Nodal and FGF pathways cooperate to maintain pluripotency of human embryonic stem cells. J Cell Sci 118: 4495-4509

87 James D, Levine AJ, Besser D, Hemmati-Brivanlou A (2005) TGFbeta/activin/ nodal signaling is necessary for the maintenance of pluripotency in human embryonic stem cells. Development 132: 1273-1282.

88 Vallier L, Mendjan S, Brown S, Chng Z, Teo A, et al. (2009) Activin/Noda signalling maintains pluripotency by controlling Nanog expression. Development 136: $1339-1349$

89 Huynh KD, Lee JT (2005) X-chromosome inactivation: a hypothesis linking ontogeny and phylogeny. Nat Rev Genet 6: 410-418.

90 Heard E (2004) Recent advances in X-chromosome inactivation. Curr Opin Cell Biol 16: 247-255

91 Hayashi K, de Sousa Lopes SM, Surani MA (2007) Germ cell specification in mice. Science 316: 394-396.

92 Maherali N, Sridharan R, Xie W, Utikal J, Eminli S, et al. (2007) Directly reprogrammed fibroblasts show global epigenetic remodeling and widespread tissue contribution. Cell Stem Cell 1: 55-70.

93 Eggan K, Akutsu H, Hochedlinger K, Rideout W, 3rd, Yanagimachi R, et al (2000) X-Chromosome inactivation in cloned mouse embryos. Science 290 1578-1581.

94 Tada M, Takahama Y, Abe K, Nakatsuji N, Tada T (2001) Nuclear reprogramming of somatic cells by in vitro hybridization with ES cells. Curr Biol 11: 1553-1558.

95 Marahrens Y, Panning B, Dausman J, Strauss W, Jaenisch R (1997) Xistdeficient mice are defective in dosage compensation but not spermatogenesis. Genes Dev 11: 156-166.

96 Penny GD, Kay GF, Sheardown SA, Rastan S, Brockdorff N (1996) Requirement for Xist in X chromosome inactivation. Nature 379: 131-137.

97 Brown CJ, Ballabio A, Rupert JL, Lafreniere RG, Grompe M, et al. (1991)Agene from the region of the human $X$ inactivation centre is expressed exclusively from the inactive $X$ chromosome. Nature 349: 38-44.

98 Brockdorff N, Ashworth A, Kay GF, Cooper P, Smith S, et al. (1991) Conservation of position and exclusive expression of mouse Xist from the inactive X chromosome. Nature 351: 329-331.

99 Borsani G, Tonlorenzi R, Simmler MC, Dandolo L, Arnaud D, et al. (1991) Characterization of a murine gene expressed from the inactive $X$ chromosome. Nature 351: 325-329.

100 Clemson CM, McNeil JA, Willard HF, and Lawrence JB (1996) XIST RNA paints the inactive $X$ chromosome at interphase: evidence for a novel RNA involved in nuclear/chromosome structure. J.Cell Biol 132: 259-275.

101 Mak W, Nesterova TB, de Napoles M, Appanah R, Yamanaka S, et al. (2004) Reactivation of the paternal $\mathrm{X}$ chromosome in early mouse embryos. Science 303: 666-669.

102 Williams LH, Kalantry S, Starmer J, Magnuson T (2011) Transcription precedes loss of Xist coating and depletion of $\mathrm{H} 3 \mathrm{~K} 27 \mathrm{me} 3$ during X-chromosome reprogramming in the mouse inner cell mass. Development 138: 2049-2057.

103 Navarro P, Chambers I, Karwacki-Neisius V, Chureau C, Morey C, et al. (2008) Molecular coupling of Xist regulation and pluripotency. Science 321: 16931695

104 Donohoe ME, Silva SS, Pinter SF, Xu N, Lee JT (2009) The pluripotency factor Oct4 interacts with $\mathrm{Ctcf}$ and also controls $\mathrm{X}$-chromosome pairing and counting. Nature 460: 128-132.

$105 \mathrm{Kim}$ DH, Jeon Y, Anguera MC, Lee JT (2011) X-chromosome epigenetic reprogramming in pluripotent stem cells via noncoding genes. Semin Cell Dev Biol 22: 336-342. 
Citation: Chen L, Zhang LF (2012) A Balanced Network: Transcriptional Regulation in Pluripotent Stem Cells. J Stem Cell Res Ther S10:004. doi:10.4172/2157-7633.S10-004

Page 10 of 10

106 Navarro P, Oldfield A, Legoupi J, Festuccia N, Dubois A, et al. (2010) Molecular coupling of Tsix regulation and pluripotency. Nature 468: 457-460.

107 Barakat TS, Gunhanlar N, Pardo CG, Achame EM, Ghazvini M, et al. (2011) RNF12 activates Xist and is essential for $\mathrm{X}$ chromosome inactivation. PLoS Genet 7: e1002001.

108 Nesterova TB, Senner CE, Schneider J, Alcayna-Stevens T, Tattermusch A, et al. (2011) Pluripotency factor binding and Tsix expression act synergistically to repress Xist in undifferentiated embryonic stem cells. Epigenetics Chromatin 4: 17

109 Tesar PJ, Chenoweth JG, Brook FA, Davies TJ, Evans EP, et al. (2007) New cell lines from mouse epiblast share defining features with human embryonic stem cells. Nature 448: 196-199.

110 Brons IG, Smithers LE, Trotter MW, Rugg-Gunn P, Sun B, et al. (2007) Derivation of pluripotent epiblast stem cells from mammalian embryos. Nature 448: 191-195.

111 Nichols J, Smith A (2009) Naive and primed pluripotent states. Cell Stem Cell 4: 487-492.

112 Guo G, Yang J, Nichols J, Hall JS, Eyres I, et al. (2009) Klf4 reverts developmentally programmed restriction of ground state pluripotency. Development 136: 1063-1069.

113 Bao S, Tang F, Li X, Hayashi K, Gillich A, et al. (2009) Epigenetic reversion of post-implantation epiblast to pluripotent embryonic stem cells. Nature 461 : 1292-1295

114 Pasque V, Gillich A, Garrett N, Gurdon JB (2011) Histone variant macroH2A confers resistance to nuclear reprogramming. EMBO J 30: 2373-2387.

115 Silva SS, Rowntree RK, Mekhoubad S, Lee JT (2008) X-chromosome inactivation and epigenetic fluidity in human embryonic stem cells. Proc Nat Acad Sci USA 105: 4820-4825.

116 Tchieu J, Kuoy E, Chin MH, Trinh H, Patterson M, et al. (2010) Female human iPSCs retain an inactive $X$ chromosome. Cell Stem Cell 7: 329-342.

117 Pomp O, Dreesen O, Leong DF, Meller-Pomp O, Tan TT, et al. (2011) Unexpected $\mathrm{X}$ chromosome skewing during culture and reprogramming of human somatic cells can be alleviated by exogenous telomerase. Cell Stem Cell 9: 156-165.

118 Cheung AY, Horvath LM, Grafodatskaya D, Pasceri P, Weksberg R, et al. (2011) Isolation of MECP2-null Rett Syndrome patient hiPS cells and isogenic controls through X-chromosome inactivation. Hum Mol Genet 20: 2103-2115.

119 Marchetto MC, Carromeu C, Acab A, Yu D, Yeo GW, et al. (2010) A model for neural development and treatment of Rett syndrome using human induced pluripotent stem cells. Cell 143: 527-539.

120 Kim KY, Hysolli E, Park IH (2011) Neuronal maturation defect in induced pluripotent stem cells from patients with Rett syndrome. Proc Natl Acad Sci USA 108: 14169-14174.

121 Lengner CJ, Gimelbrant AA, Erwin JA, Cheng AW, Guenther MG, et al. (2010) Derivation of pre-X inactivation human embryonic stem cells under physiological oxygen concentrations. Cell 141: 872-883.

122 Ware CB, Wang L, Mecham BH, Shen L, Nelson AM, et al. (2009) Histone deacetylase inhibition elicits an evolutionarily conserved self-renewal program in embryonic stem cells. Cell Stem Cell 4: 359-369.

123 Hanna J, Cheng AW, Saha K, Kim J, Lengner CJ, et al. (2010) Human embryonic stem cells with biological and epigenetic characteristics similar to those of mouse ESCs. Proc Natl Acad Sci USA 107: 9222-9227.

124 Okamoto I, Patrat C, Thepot D, Peynot N, Fauque P, et al. (2011) Eutherian mammals use diverse strategies to initiate $\mathrm{X}$-chromosome inactivation during development. Nature 472: 370-374.

125 van den Berg IM, Laven JS, Stevens M, Jonkers I, Galjaard RJ, et al. (2009) X chromosome inactivation is initiated in human preimplantation embryos. Am J Hum Genet 84: 771-779.

126 Sridharan R, Tchieu J, Mason MJ, Yachechko R, Kuoy E, et al. (2009) Role of the murine reprogramming factors in the induction of pluripotency. Cell 136 364-377.

127 Feng B, Jiang J, Kraus P, Ng JH, Heng JC, et al. (2009) Reprogramming of fibroblasts into induced pluripotent stem cells with orphan nuclear receptor Esrrb. Nat Cell Biol 11: 197-203.

128 Silva J, Barrandon O, Nichols J, Kawaguchi J, Theunissen TW, et al. (2008) Promotion of reprogramming to ground state pluripotency by signal inhibition. PLoS Biol 6: e253.

129 Marson A, Foreman R, Chevalier B, Bilodeau S, Kahn M, et al. (2008) Wn signaling promotes reprogramming of somatic cells to pluripotency. Cell Stem Cell 3: 132-135.

130 Ichida JK, Blanchard J, Lam K, Son EY, Chung JE, et al. (2009) A smallmolecule inhibitor of tgf-Beta signaling replaces sox2 in reprogramming by inducing nanog. Cell Stem Cell 5: 491-503.

131 Li W, Wei W, Zhu S, Zhu J, Shi Y, et al. (2009) Generation of Rat and Human Induced Pluripotent Stem Cells by Combining Genetic Reprogramming and Chemical Inhibitors. Cell Stem Cell 4: 16-19.
This article was originally published in a special issue, Embryonic and Induced Pluripotent Stem Cells handled by Editor(s). Dr. Jianlong Wang, Mount Sinai School of Medicine, United States 